\title{
НОРМЫ КОРПОРАТИВНОГО ПРАВА ЕВРОПЕЙСКОГО СОЮЗА И ОСОБЕННОСТИ ОРГАНИЗАЦИИ И ВЕДЕНИЯ БИЗНЕСА
}

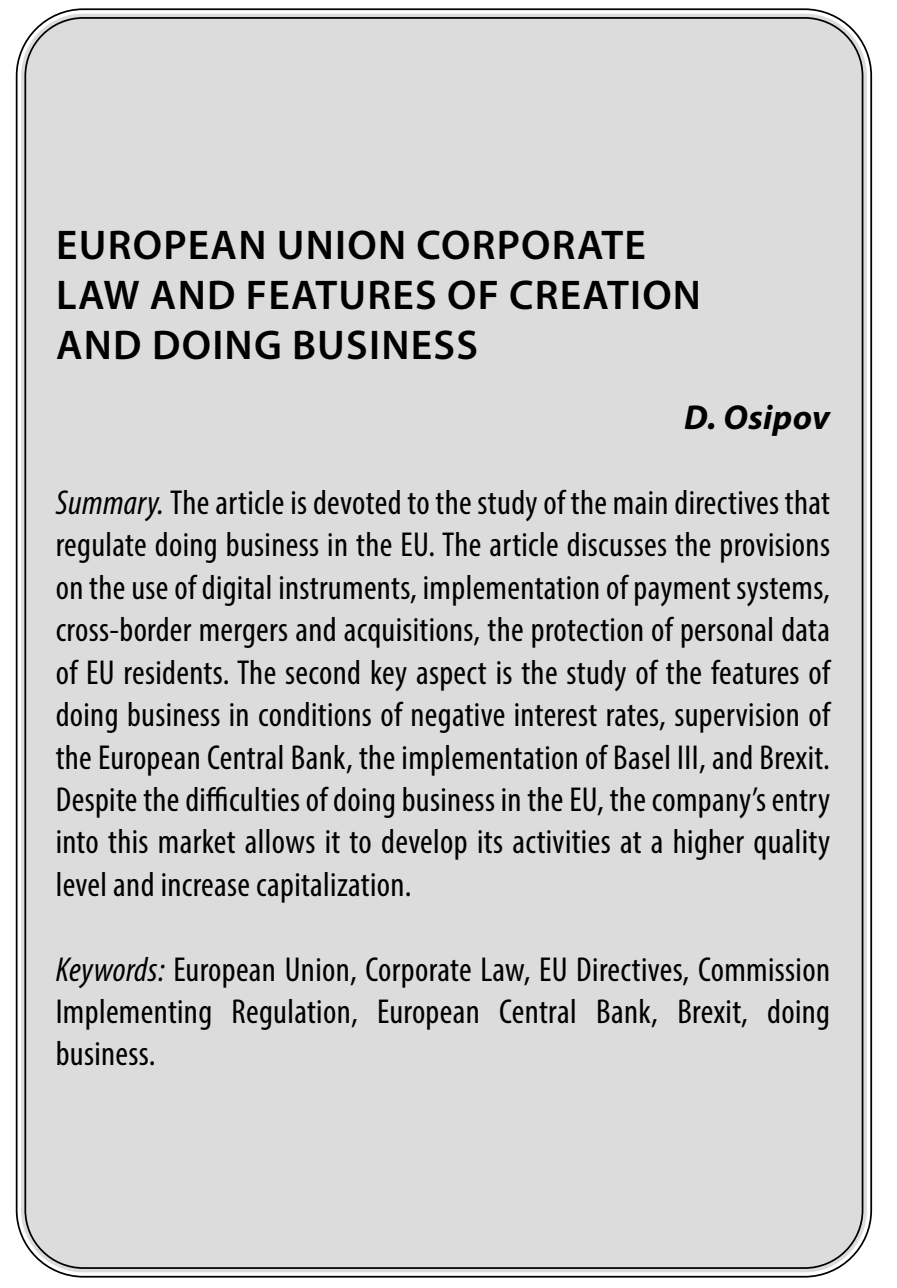

$\boldsymbol{9}$ кономики стран-членов Европейского Союза (ЕС) растут, создавая новые возможности для ведения бизнеса. Выстраивание отношений с компаниями, которые являются резидентами ЕС, а также открытие своих представительств на его территории, создает имидж и позволяет получать более существенные прибыли. Тем не менее, компаниям необходимо учитывать политические, экономические изменения, которые происходят в границах ЕС, принятие новых директив, чтобы эффективно работать, сохранять лидерство в своих сферах и повышать капитализацию.

Для выстраивания отношений и ведение дел в ЕС требуется знание тонкостей корпоративного законодательства. Компании предпочитают нанимать юридические фирмы, которые специализируются в этой отрасли права и оказывают поддержку как на начальном этапе

\author{
Осипов Даниил Владимирович \\ К.филол.н., дочент, ФГБОУ ВО «Астраханский \\ государственный университет» \\ d.osipov@asu.edu.ru
}

Аннотация. Статья посвящена изучению основных директив, которые регламентируют ведение бизнеса на территории ЕС. В статье рассматриваются положения по использованию цифровых инструментов, платежные системы, трансграничные слияния и поглощения, защита персональных данных резидентов ЕС. Вторым ключевым аспетом является исследование особенностей ведения бизнеса в условиях отрицательных процентных ставок, надзора Европейского центрального банка, введения в действие правил Базеля III, обособления Великобритании. Несмотря на сложности ведения бизнеса на территории ЕС, выход компании на данный рынок позволяет развивать свою деятельность на более качественном уровне, увеличивая капитализацию.

Ключевые слова: Европейский союз, корпоративное право, директивы ЕС, регламенты Комиссии, Европейский центральный банк, Brexit, ведение бизнеса.

выхода на рынок ЕС, так и консультативную помощь в процессе ведения дел.

Цель данной статьи является рассмотрение основных директив, которые регламентируют ведение бизнеса на территории ЕС с учетом требований по цифровизации и обращения с персональными данными резидентов стран-членов ЕС, а также выделение некоторых особенностей, которые стоит учитывать, при создании представительств и выходе на европейский рынок.

Корпоративное право ЕС охватывает такие аспекты, как процедура создания компании, требования к минимальному капиталу и раскрытию информации, а также операциям по слиянию компаний. Необходимо отметить, что данная отрасль права развивается достаточ- 
но медленно в связи с расхождениями во внутреннем законодательстве стран-членов ЕС. В настоящее время большая часть законов ЕС о компаниях кодифицирована в единой Директиве - Директиве Европейского Парламента и Совета Европейского Союза 2017/1132 от 14.06.2017 «О некоторых аспектах корпоративного права» [1].

Директива 2019/1151 от 20 июня 2019 года охватывает положения об использовании цифровых инструментов и процессов в корпоративном праве. Государства-члены должны транспонировать эту Директиву к августу 2021 года (с более длительным сроком для некоторых конкретных положений) [2]. Директива (ЕС) 2019/2121 от 27 ноября 2019 года устанавливает новые правила международного обращения и вносит поправки в правила трансграничных слияний [3]. Государства-члены должны транспонировать эту Директиву к январю 2023 года. Этот новый набор правил позволит компаниям использовать цифровые инструменты в процедурах корпоративного права, а также реструктурировать и осуществлять трансграничное сотрудничество, гарантируя при этом защиту от мошенничества. Эти новые Директивы пересматривают и дополняют Директиву 2017/1132.

Директива 2012/17/EC [4] и Исполнительный регламент Комиссии (EC) 2015/884 [5] устанавливают правила системы взаимосвязи коммерческих регистров («BRIS»). BRIS работает с 8 июня 2017 года, обеспечивая электронный доступ к информации о компаниях и документам, хранящимся в коммерческих реестрах государств-членов ЕС, через Европейский портал электронного правосудия. BRIS также позволяет регистрам предприятий обмениваться между собой уведомлениями о трансграничных операциях и о филиалах.

Директива Европейского Парламента и Совета Европейского Союза 2009/102/ЕС от 16.09.2009 в сфере корпоративного права регулирует деятельность частных компаний с ограниченной ответственностью с одним участником [6].

Два Регламента устанавливают правила для юридических лиц в ЕС:

- Регламент Совета Европейского Союза 2157/2001 от 08.10.2001 «О Статуте Европейской компании (SE)» устанавливает правовую форму для публичных компаний с ограниченной ответственностью, и позволяет компаниям из разных стран-участниц вести свой бизнес в ЕС под единой европейской торговой маркой [7].

- Регламент 2137/85 устанавливает законоположение для Европейского объединения с общей экономической целью (EEIG), то есть правовую форму для группы, образованной компаниями или юридическими лицами и/или физическими лицами, осуществляющими экономическую деятельность из разных государств-членов; цель такого объединения - способствовать или развивать трансграничную экономическую деятельность ее членов [8].

В законодательстве в сфере корпоративного права EC также затронуты вопросы корпоративного управления, уделяется особое внимание взаимоотношениям между руководством компании, советом директоров, акционерами и другими заинтересованными сторонами и, следовательно, способам управления и контроля компании.

Директива о правах акционеров 2007/36/ЕС устанавливает определенные права для акционеров публичных компаний [9]. Данная Директива была дополнена Директивой (ЕС) 2017/828, в которой оговариваются поощрения при взаимодействии с акционерами, особенно в долгосрочной перспективе. Кроме того, Исполнительный регламент Комиссии 2018/1212 (ЕС) устанавливает минимальные требования в отношении идентификации акционеров, передачи информации и облегчает осуществление прав акционеров [10].

Директива Европейского Парламента и Совета Европейского Союза 2004/25/ЕС от 21.04.2004 «О предложениях по поглощению» устанавливает правила по поглощению (или смены контроля), включая порядок обращения с ценными бумагами компаний ЕС [11].

Вопросы корпоративного управления также были определены как важная область, на которой следует сосредоточить внимание в контексте реализации Плана действий ЕС по финансированию устойчивого роста, и, в частности, Действия 10. В соответствии с общей целью Комиссии по справедливому переходу к устойчивой экономике и восстановлению после COVID, Зеленый пакт для Европы и План восстановления подтверждают важность включения в них понятия «устойчивость» в корпоративное управление. Инициативу устойчивого корпоративного управления планируется предложить в 2021 году [12].

К банкам и инвестиционным компаниям применяются особые правила корпоративного управления. Цель этих правил - ограничить риски и тем самым помочь обеспечить финансовую стабильность.

Информацию о правилах корпоративного управления в банках и системных инвестиционных компаниях можно найти в Директиве о требованиях к капиталу (Директива 2013/36/ЕС с поправками, внесенными Директивой 2019/878/EC) и Положении о требованиях 
к капиталу (Постановление № 575/2013 с поправками, внесенными Постановлением № 2019/876) [13].

Информацию о правилах корпоративного управления в несистемных инвестиционных компаниях можно найти в Директиве об инвестиционных компаниях (Директива 2019/2034) и Положении об инвестиционных компаниях (Регламент 2019/2033) [14].

Таким образом, в то время как компании системного инвестирования остаются в рамках банковских правил, фирмы несистемного инвестирования подчиняются отдельному режиму. Это связано с тем, что Комиссия обнаружила, что пруденциальная система для банков не адаптирована к бизнес-модели этих инвестиционных фирм.

Открытие представительств компаний и ведение бизнеса с партнерами из ЕС - это своего рода статус и возможности получать дополнительные прибыли, развиваясь в высококонкурентной среде, тем не менее, помимо директив и регламентов ЕС, при выходе на рынки стран-членов ЕС следует учитывать ряд аспектов, которые попадают как в правовую, так и экономическую сферы:

1. Отрицательные процентные ставки преобладают в Еврозоне, Швейцарии, Швеции и Дании, и в краткосрочной перспективе не произойдут изменения [15]. В результате большинство банков теперь берут комиссию с клиентов, у которых есть остатки на счетах в этих валютах. Клиентов просят вывести из банка неоперационные активы или им определяют порог, которого они должны придерживаться. В ответ клиенты находят применение своим лишним наличным деньгам. Согласно недавнему опросу компаний, базирующихся в EC, большинство финансовых директоров использует эти средства для расширения своих продуктовых линеек, выхода на новые рынки или приобретения бизнеса. Другими словами, идет расходование этих денежных средств.

Часть компаний внедряют более агрессивные стратегии для управления своими избыточными денежными средствами, например, кредитование внутри фирмы, оплата счетов от других организаций этими средствами, создание собственных банков или перевод наличных денег в другие валюты, чтобы снизить риск наличия избыточных средств в банках некоторых стран Европы. Компании также учитывают недавние налоговые изменения в США и других странах при определении того, сколько денег следует хранить за границей.

Становится все более важным понимать, где и когда появляются лишние денежные средства, изучать стра- тегии хеджирования, поскольку в последнее время курсы европейских валют сильно колеблются.

2. Европейские банки гораздо больше зависят от краткосрочных заимствований для финансирования своих потребностей в капитале, чем, например, банки США. Депозиты и заимствования - два основных источника средств для банков; там, где существует конкуренция за вклады, банкам приходится полагаться на заимствования. В результате многие европейские банки имеют высокие индикаторы долгосрочной ликвидности [16].

С 4 ноября 2014 года Европейский центральный банк (ЕЦБ) получил надзорную роль для мониторинга финансовой стабильности банков в еврозоне через Единый надзорный механизм (SSM) в соответствии с Регламентом ЕС 1024/2013 [17]. ЕЦБ обладает полномочиями проводить надзорные проверки, проверки на местах и расследования; предоставлять и отзывать банковские лицензии; оценивать банковские приобретения; обеспечить соблюдение пруденциальных правил ЕС; и при необходимости устанавливать более высокие требования к капиталу для противодействия финансовым рискам.

Некоторые из этих регулирующих действий могут привести к сдерживанию роста в европейских странах и сокращению кредитования банками. Это необходимо отслеживать для принятия решения о том, где в Европе работать и сосредоточить свои ресурсы.

3. В большинстве европейских стран практически отсутствуют чеки, за исключением Франции и вышедшей из ЕС Великобритании. Инструмент, называемый жиро, все еще используется в некоторых странах, наличные деньги становятся все менее популярны.

Использование электронных платежных систем в Великобритании и других странах ЕС достаточно распространено, и существует множество средств контроля для защиты отправителей. В последние годы платежные платформы развивались в ЕС и Великобритании намного быстрее, чем в США [18]. Такие платформы, как SEPA (Единая зона платежей в евро), SEPA Inst и Faster Payments (Великобритания) способствовали ускорению и удешевлению внутригосударственных и международных платежей. SEPA берет небольшую комиссию за перевод и использует единый оптимизированный формат в EC.

Brexit в той или иной степени повлиял на комиссии при осуществлении платежей и потенциальный доступ ко всей схеме платформ. Переговоры продолжаются и, вероятно, будут определены новые условия. 
4. Достаточно сложно открывать счета нерезидентам (нерезидент означает, что у компании нет юридического лица, созданного в той или иной стране-члене EC, но все же может потребоваться открыть счет в банке этой страны). Широкое распространение во всем мире принципа «знай своих клиентов» увеличило затраты банков на соблюдение нормативных требований при работе с клиентами. Считается, что с компаниями без сотрудников на местах слишком сложно работать с точки зрения проверки личности корпоративных представителей, и поэтому многие банки не открывают счета для таких предприятий.

5. Некоторые страны ЕС требуют открытия счета движения капитальных средств и внесения минимального подписного капитала для создания европейского предприятия [19]. В каждой стране могут быть разные требования и минимальные размеры подписного капитала, часто это зависит от типа создаваемой организации. Компаниям необходимо работать с юрисконсультом для создания юридических лиц в ЕС.

6. Налог на добавленную стоимость (НДС) может быть возвращен как для компаний-нерезидентов, так и для компаний-резидентов в Европе [20]. В зависимости от типа компании в некоторых странах, например, в Италии, для возврата НДС необходимо открыть счет внутри страны.

В ноябре 2017 года Европейский совет по платежным системам опубликовал отчет о разграничении международных номеров банковских счетов в том числе для НДС в ЕС [21]. Это применимо к компаниям, от которых определенные налоговые органы требуют открытия счетов в странах Европы, где они пытаются платить НДС, что, по сути, не позволено. Регламент EPC гласит, что клиент может использовать SEPA IBAN в любой из стран, совместимых с SEPA, для совершения и получения этих платежей. Компании должны понимать, как взимается НДС в разных странах, включая любые банковские требования.

7. Объединение денежных средств (кеш-пулинг) это практика, которая позволяет корпорациям управлять своей глобальной ликвидностью с меньшими затратами в различных бизнес-структурах, которые подпадают под единый бренд корпорации. Эта структура становится все более распространенной для многих транснациональных корпораций. Компании структурируют свои денежные механизмы между дочерними предприятиями, чтобы компенсировать дефицит денежных средств одной компании излишками денежных средств другой. Это может упростить управление денежными средствами и ликвидностью и снизить общие банковские сборы [22].
Одна из форм кэш-пулинга - номинальный пул, очень популярна во многих европейских странах. Номинальный пул позволяет проводить взаимозачет процентных доходов и расходов, возникающих в результате различий в денежных позициях каждой дочерней или юридической компании, хранящей средства на отдельных банковских счетах в одном и том же банке. Каждая организация, участвующая в пуле, ведет свои собственные счета.

Банк создает «бумажную» или номинальную позицию из всех счетов участников, в результате чего получается консолидированная денежная позиция, по которой выплачиваются или начисляются проценты.

В связи с введением в действие правил Базеля III в Европе многие банки пришли к выводу, что предложение данного продукта и соблюдение требований Базеля к капиталу обходятся слишком дорого. Компании, работающие по всей Европе, которые используют одну или несколько валют, должны обсудить со своими финансовыми консультантами преимущества физического или номинального объединения денежных средств.

8. В Европе овердрафты часто используются как способ финансирования оборотного капитала. В 2017 году кредитные линии, в том числе банковские овердрафты, были наиболее распространенной формой финансирования, используемой европейскими МСП (малыми и средними предприятиями) [23].

Кредитные линии по овердрафту могут быть дорогостоящими для европейских дочерних компаний или деловых партнеров, а также станет проблемой, если прибыльность этих организаций начнет падать. Важно понимать финансовые потребности дочерних компаний и устанавливать правила внутри компании по заимствованиям.

9. При ведении бизнеса в Европе необходимо учитывать несколько нормативных изменений, в том числе:

\section{Обособление Великобритании [24]}

Имеет место быть структурное разделение банков, занимающихся индивидуальным и коммерческим размещением депозитов, банки стремятся сократить рискованные операции.

В связи с отделением Великобритании некоторым банкам и другим депозитным учреждениям, возможно, придется реорганизовать свою структуру и изменить некоторые из своих банковских функций. Это может привести к ограничению доступа к финансированию и услугам или возникнет необходимость смены банка. 


\section{$\triangle$ иректива}

\section{о платежных услугах (PSD2) [25]}

PSD2 - это пересмотренная версия Директивы о платежных услугах, выпущенная в январе 2018 года. Первоначальная версия была принята в 2007 году и легла в основу платежной системы SEPA.

PSD2 включает несколько улучшений:

- устраняет барьеры для входа, дает возможность для продвижения новых участников, а также улучшает конкурентоспособность;

- повышает безопасность системы, включая улучшенную аутентификацию клиентов;

- не ограничена рамками EC;

- включает юридическое требование о возврате средств за ошибочные транзакции и запрет на доплаты за транзакции;

- ограничивает неавторизированные платежи.

Компаниям необходимо предоставить подтверждение, что их европейские партнеры и дочерние компании, а также их банк своевременно внедряют эти улучшения.

Общий регламент EC по защите персональных данных (GDPR) [26].

Все банки и предприятия, работающие в ЕС, в том числе в Великобритании, должны будут соблюдать новые правила, касающиеся безопасности данных.

B статье 3 GDPR оговаривается, что при сборе персональных данных в стране ЕС, компания подчиняется требованиям GDPR. Закон применяется только в том случае, если субъекты данных (поскольку GDPR относится к потребителям) находятся в ЕС на момент сбора данных.

Финансовая транзакция не обязательна для того, чтобы попасть под действие закона. Если организация просто собирает «личные данные» в рамках маркетингового исследования, тогда данные тоже должны быть защищены требованиями GDPR.

Основным изменением GDPR является территориальная сфера действия нового закона. GDPR заменяет Директиву ЕС о защите данных 1995 [27], которая не регулировала деятельность предприятий, находящихся за пределами ЕС. Теперь, даже если у компании нет сотрудников или офисов в странах-членах EC, GDPR все равно может применяться.

Согласно GDPR, компания подпадает под действие нового закона, если она обрабатывает персональные данные физического лица, проживающего в ЕС. Это тот случай, когда обработка связана с предложением това- ров или услуг или мониторингом поведения, которые имеют место быть в странах-членах ЕС [28].

Новые правила GDPR вступили в силу 25 мая 2018 г., важно убедиться, что партнеры и банк их соблюдает.

Вторая Директива о рынках финансовых инструментов (Mifid II) [29]. Первая Директива о рынках финансовых инструментов вступила в силу в 2007 году. Она включает положения по идентификации клиентов и требования к категоризации, правила обработки клиентских заказов, требования к прозрачности до и после торговых операций, а также требования к инвестиционным компаниям.

Mifid II фокусируется на регулировании торговых площадок и процессов на всей территории ЕС. В этой директиве, которая вступила в силу в январе 2018 г., основное внимание уделялось усовершенствованному и стандартизированному управлению и процессам.

14. В связи с выходом из ЕС Великобритании при ведении бизнеса со странами-членами ЕС и Соединенным Королевством следует учитывать:

- колебание курсов валют с целью хеджирования рисков;

- изменение правил перемещения сотрудников компаний из Великобритании на континент и обратно;

- изменение цепочек поставок товаров и цепочек добавленной стоимости в связи с увеличением стоимости перемещения товаров и услуг через границы.

Таким образом, на основе рассмотрения нормативно-правовой базы источников регулирования отношений в сфере создания и ведения бизнеса на территории ЕС можно сделать вывод, что законодательство ЕС В области корпоративного права является достаточно эффективным и обширным, определяет отношения между компаниями, а также государственными органами, особое внимание уделяется защите прав потребителя, включая его личные данные. Немаловажным является учет особенностей ведения дел на территории стран-членов ЕС, так как при стремлении к унификации правовой базы, все еще остается достаточно аспектов, которые имеют различия в государствах, входящих в ЕС.

This article was supported by the Erasmus+ programme of the European Union (Jean Monnet 599815-EPP-1-RUEPPJMO-MODULE).

The European Commission's support for the production of this publication does not constitute an endorsement of the contents, which reflect the views only of the authors, and the Commission cannot be held responsible for any use which may be made of the information contained therein. 


\section{ЛИТЕРАТУРА}

1. Directive (EU) 2017/1132 of the European Parliament and of the Council. URL: https://eur-lex.europa.eu/legal-content/EN/ALL/?uri=celex\%3A32017L1132 (дата обращения 26.06.2021).

2. Directive (EU) 2019/1151 of the European Parliament and of the Council. URL: https://eur-lex.europa.eu/eli/dir/2019/1151/0ј (дата 0бращения 26.06.2021).

3. Directive (EU) 2019/2121 of the European Parliament and of the Council. URL: https://eur-lex.europa.eu/eli/dir/2019/2121/ој (дата обращения 26.06.2021).

4. Directive 2012/17/EU of the European Parliament and of the Council. URL: https://eur-lex.europa.eu/eli/dir/2012/17/oj (дата 0бращения 26.06.2021).

5. Commission Implementing Regulation (EU) 2015/884. URL: https://eur-lex.europa.eu/eli/reg_impl/2015/884/ој (дата 0бращения 26.06.2021).

6. Directive 2009/102/EC of the European Parliament and of the Council. URL: https://eur-lex.europa.eu/legal-content/en/ALL/?uri=CELEX:32009L0102 (дата обращения 26.06.2021).

7. Регламент N2157/2001 Совета Европейского Союза «0 Статуте Европейской компании (SE)». URL: http://www.consultant.ru/cons/cgi/online.cgi?req=doc \&base $=$ INT\&n=54904\#09094674592414291 (дата обращения 26.06.2021).

8. Регламент N2137/85 Совета Европейских сообществ «0 Европейском объединении с общей экономической целью». URL: http://www.consultant.ru/ cons/cgi/online.cgi?req=doc\&base=INT\&n=53135\#05864263230173585 (дата обращения 26.06.2021).

9. Directive 2007/36/EC of the European Parliament and of the Council. URL: https://eur-lex.europa.eu/legal-content/EN/TXT/?uri=celex\%3A32007L0036 (дата обращения 26.06.2021).

10. Commission Implementing Regulation (EU) 2018/1212. URL: https://eur-lex.europa.eu/legal-content/EN/TXT/?uri=CELEX\%3A32018R1212 (дата 0бращения 26.06.2021).

11. Directive 2004/25/EC of the European Parliament and of the Council. URL: https://eur-lex.europa.eu/legal-content/EN/TXT/?uri=celex\%3A32004L0025 (дата обращения 26.06.2021).

12. European Green Deal. URL: https://ec.europa.eu/info/strategy/priorities-2019-2024/european-green-deal_en (дата 0бращения 26.06.2021).

13. Directive 2013/36/EU of the European Parliament and of the Council. URL: https://eur-lex.europa.eu/legal-content/EN/TXT/?uri=celex\%3A32013L0036 (дата обращения 26.06.2021).

14. Directive (EU) 2019/2034 of the European Parliament and of the Council. URL: https://eur-lex.europa.eu/legal-content/EN/TXT/?uri=CELEX\%3A32019L2034 (дата обращения 26.06.2021).

15. Negative Interest Rates. URL: https://www.bloomberg.com/quicktake/negative-interest-rates (дата обращения 01.07.2021).

16. European Banks vs. US Banks: Big Differences. URL: https://www.cnbc.com/id/37237500 (дата обращения 01.07.2021).

17. Council Regulation (EU) No 1024/2013. URL: https://eur-lex.europa.eu/legal-content/EN/TXT/HTML/?uri=CELEX:32013R1024\&from=BG (дата 0бращения 01.07.2021).

18. The 2020 McKinsey Global Payments Report. URL: https://www.mckinsey.com/ /media/mckinsey/industries/financial\%20services/our\%20insights/ accelerating\%20winds\%20of\%20change\%20in\%20global\%20payments/2020-mckinsey-global-payments-report-vf.pdf (дата 0бращения 07.07.2021).

19. Setting up a European Company (SE). URL: https://europa.eu/youreurope/business/start-grow/european-company-legal-form/index_en.htm (дата 0бращения 07.07.2021).

20. European VAT refund guide 2019. URL: https://www2.deloitte.com/content/dam/Deloitte/global/Documents/Tax/dttl-tax-european-vat-refund-guide.pdf (дата обращения 07.07.2021).

21. Report from the Commission to the European Parliament and the Council. URL: https://ec.europa.eu/info/sites/info/files/171123-report-sepa-requirements en.pdf (Section 2.3) (дата обращения 07.07.2021).

22. CAsh PoolinG — Treasury Alliance Group. URL: https://static1.squarespace.com/static/5ffe43058b11df4bbed1429c/t/6000a4bd6dff0623491e7 3f9/1610654910245/Treasury_Alliance_cash_pooling_white_paper.pdf (дата обращения 08.07.2021).

23. SAFE report 2017-Infographic SME EU resultsю URL: https://ec.europa.eu/docsroom/documents/26625 (дата обращения 08.07.2021).

24. RING-FENCING: The Challenges Facing UK Banks. URL: http://en.finance.sia-partners.com/20170619/ring-fencing-challenges-facing-uk-banks (дата 0бращения 08.07.2021).

25. PSD2: What's new and what is changing? URL: https://www.smartdebit.co.uk/psd2-april-2017-changes-info/ (дата 0бращения 08.07.2021).

26. General Data Protection Regulation. URL: https://gdpr-info.eu (дата обращения 03.07.2021).

27. Directive 95/46/EC of the European Parliament and of the Council. URL: https://eur-lex.europa.eu/legal-content/en/TXT/?uri=CELEX\%3A31995L0046 (дата обращения 02.07.2021).

28. A Summary of the EU General Data Protection Regulation. URL: https://www.dataiq.co.uk/blog/summary-eu-general-data-protection-regulation (дата 0бpaщения 03.07.2021).

29. An Overview of MiFID II. URL: http://www.publications.kbassociates.ie/an-overview-of-mifid-ii/ (дата обращения 08.07.2021).

(с) Осипов Даниил Владимирович ( d.osipov@asu.edu.ru ).

Журнал «Современная наука: актуальные проблемы теории и практики» 